\title{
MRPLI 3 is a Prognostic Cancer Biomarker and Correlates with Immune Infiltrates in Breast Cancer
}

This article was published in the following Dove Press journal: OncoTargets and Therapy

\section{Zuo Tao* \\ Huandan Suo* \\ Lei Zhang \\ Zining Jin \\ Zhen Wang \\ Danyu Wang \\ Ming Wu (D) \\ Nanxi Peng \\ Yujie Zhao (D) \\ Bo Chen (ID)}

Department of Breast Surgery, The First Hospital of China Medical University, Shenyang, Liaoning Province II000I,

People's Republic of China

*These authors contributed equally to this work
Correspondence: Zuo Tao; Bo Chen Department of Breast Surgery, The First Hospital of China Medical University, I55 North Nanjing Street, Heping District, Shenyang, Liaoning Province II000I,

People's Republic of China

Email bochen@cmu.edu.cn; taozuocmu@।63.com
Objective: To study the expression of MRPL13 in breast cancer tissues using TCGA database, analyze the correlation between the expression and clinicopathological characteristics of patients, and explore the role of MRPL13 in the development of breast cancer (BC). Methods: The BC mRNA data and clinical information were downloaded from TCGA database. The correlation between MRPL13 expression and clinicopathological parameters was analyzed. Cox regression multivariate analysis was used to explore the factors affecting the prognosis of $\mathrm{BC}$ patients. The UALCAN database was used to analyze the expression level of MRPL13 in BC and its relationship with clinical pathological factors. The GSEA method was used to predict the possible regulatory pathways of MRPL13. Immune responses of MRPL13 expression were analyzed using TISIDB and CIBERSORT. Additionally, GEPIA, K-M survival analysis and data from the HPA were used to validate the outcomes.

Results: The expression of MRPL13 in BC tissues was significantly higher than normal counterparts, patients with low MRPL13 expression had a better survival prognosis, also indicated an independent prognostic factor. GSEA analysis showed that the regulation of cell migration, positive regulation of endothelial cell migration, and Notch signaling pathway were enriched in tissues with low expression of MRPL13. Additionally, depleting MRPL13 expression inhibited invasion in MCF-10A and MCF-7 cells. Furthermore, PCR showed that MRPL13 affected VEGFA and MMP gene expression. CIBERSORT analysis revealed that the amount of NK cells decreased when MRPL13 expression was high.

Conclusion: The expression of MRPL13 mRNA is upregulated in $\mathrm{BC}$ tissues, and the expression level of MRPL13 is significantly related to the clinicopathological factors of patients. High MRPL13 expression is a poor prognostic factor for $\mathrm{BC}$, and it can be used as a molecular marker for prognosis judgment and as a potential therapeutic target.

Keywords: cancer genome map, breast cancer, $M R P L 13$, clinical significance

\section{Introduction}

Breast cancer (BC) is one of the most common malignant tumors in women. Its incidence rate ranks first among the common tumors of women, and its mortality rate ranks second. ${ }^{1}$ In recent years, the survival of $\mathrm{BC}$ patients has been greatly improved, but there are still some patients with a poor prognosis and the incidence has been increasing yearly. ${ }^{2}$ Therefore, an in-depth study of the pathogenesis of BC and identification of a highly sensitive molecular marker can be of great significance for the early diagnosis and prognosis of BC.

Despite advances in screening and diagnosis and treatment technologies in recent years that have largely improved the survival rate of $\mathrm{BC}$ patients, it remains one of the major diseases with the highest female mortality rate and huge individual 
differences exist in the treatment results. ${ }^{3}$ Most current genetic prognosis prediction schemes are based on gene chips, which, while lacking specificity, may cause additional economic burden to patients. ${ }^{4}$ Therefore, it is of great clinical significance to discover more accurate and economical new biomarkers for prognosis prediction.

Multiple studies have found that mitochondrial dysfunction or disorders can cause various diseases. ${ }^{5}$ Depending on the degree of dependence of different tissues and organs on the mitochondria, different tissuespecific manifestations occur, such as tumors, cardiovascular diseases, hearing disorders, neurological diseases, developmental disorders, sensory disorders, and metabolic disorders. ${ }^{6-8}$ Mitochondria are organelles that produce the energy required by cells and play a key role in cell energy metabolism. ${ }^{9}$ Mitochondrial ribosomal proteins (MRPs) exist in the mitochondria of eukaryotic cells. ${ }^{10}$ After synthesis in the cytoplasm, they are transported from the cytoplasmic matrix to the mitochondria to complete the assembly of mitochondrial ribosomes and participate in the translation process of mitochondrial proteins. ${ }^{11,12}$ Mitochondrial ribosomal proteins are also involved in various cell life activities, including mitochondrial homeostasis regulation, cell differentiation, cell information transmission, and apoptosis. ${ }^{13,14}$ Mitochondrial dysfunction is closely related to tumorigenesis and development. ${ }^{15}$ Many MRPs have been found to be elevated in tumors. ${ }^{12}$ For example, high MRPL35 expression in colon cancer related to shorter overall survival and depletion of MRPL35 led to increased production of reactive oxygen species correlated with DNA damage, loss of cell proliferation, $\mathrm{G} 2 / \mathrm{M}$ arrest, a decrease in mitochondrial membrane potential, apoptosis, and autophagy induction. ${ }^{16}$ MRPL41 protein stabilizes $p 53$ and enhances its translocation to the mitochondria to induce apoptosis. Additionally, MRPL41 stabilizes Kip1 and arrests the cell cycle at the G1 phase in the absence of $p 53 .{ }^{17}$ Another study showed that MRPL41 arrests the cell cycle by increasing $p 21$ and p27 levels under growth-inhibitory conditions. ${ }^{18}$

The Cancer Genome Atlas (TCGA) database is a multiomics database that contains the genome, transcriptome, proteomics, and epigenomics data, as well as the associated clinical data, of different cancers. This study demonstrated the expression of mitochondrial ribosomal protein L13 (MRPL13) in BC tissues using The Cancer Genome Atlas (TCGA) database, analyzed its impact on patient prognosis, and explored its clinical value.

\section{Materials and Methods Data Collection}

The Bioconductor/TCGA biolinks function package was used to download the BC RNA seq expression profile data from the TCGA database (https://portal.gdc.cancer.gov/). We used Perl script to combine the RNA seq data and transform the gene symbols. The BC mRNA data set comprised 1066 samples, of which 112 were paired samples adjacent to the tumor. The matched tumor and adjacent samples were selected according to the number of paired samples for the analysis of differential mRNA. The EdgR package in $\mathrm{R}$ software was used to normalize the data and screen for differential mRNAs. The screening conditions were $\mathrm{P}$ value $<0.05$ and $|\operatorname{logFC}|>2$. The relative expression of MRPL13 was analyzed, and the clinical data of BC were downloaded from the TCGA database; the gender, age, TNM stage were selected for later screening. The gene expression value of MRPL13 was matched with the clinical data according to the sample number, and then the data were sorted using $\mathrm{R}$ software to obtain a baseline table of clinical data for subsequent Cox univariate and multifactor analyses. The project protocol was approved by the Institutional Ethics Committee of China Medical University before initiation of the study, and all patients provided a written informed consent for the use of the tumor tissues for clinical research.

\section{Analysis of Clinicopathological Parameters and Gene Set Enrichment}

By screening clinical data, cases with unknown or incomplete clinicopathological parameters and cases lacking prognostic follow-up data were excluded, and only those cases that included clinical parameters and survival data in the TCGA data set were retained. Finally, the data of 860 cases containing complete clinicopathological parameters and survival data were obtained. According to the mRNA sequencing data, the MRPL13 mRNA expression level greater than the median value in $\mathrm{BC}$ tissue was defined as high MRPL13 expression; otherwise, it was defined as low MRPL13 expression; gene set enrichment analysis (GSEA) software was used for analysis. According to the method in 1.2, the cases were divided into the MRPL13 high expression group and MRPL13 low expression group according to the expression level of MRPL13. In this study, the c2.cp.kegg.v7.0.symbols.gmt, c5.all.v7.0.symbols.gmt, and c7.all.v7.0.symbols.gmt data sets were obtained from the MsigDB database of the GSEA website. 
Next, enrichment analysis was performed according to the default weighted enrichment statistics method, and the number of random combinations was set to 1000 times.

\section{Quantitative Real-Time PCR (SYBR Green Method)}

Quantitative real-time PCR was performed using SYBR Green PCR master mix (Applied Biosystems) in a total volume of $20 \mu \mathrm{L}$ using the $7900 \mathrm{HT}$ fast real-time PCR system (Applied Biosystems) as follows: $50^{\circ} \mathrm{C}$ for $2 \mathrm{~min}$, $95^{\circ} \mathrm{C}$ for $10 \mathrm{~min}, 40$ cycles of $95^{\circ} \mathrm{C}$ for $15 \mathrm{~s}$, and $60^{\circ} \mathrm{C}$ for $60 \mathrm{~s}$. The sequences of the primer pairs were as follows: matrix metalloproteinase $2(M M P-2)$ forward, 5'-ACGA ATTTGCCGACAGAGATG-3', $M M P-2$ reverse, 5'GGGTATCCGTGTAGCACATTCT-3'; vascular endothelial growth factor A (VEGFA) forward, 5'- GGCCTCCG AAACCATGAACT-3', VEGFA reverse, 5'- TCGTGATG ATTCTGCCCTCC -3'; GAPDH forward, 5'- ATAGCA CAGCCTGGATAGCAACGTAC -3', GAPDH reverse, 5'- CACCTTCTACAATGAGCTGCGTGTG-3'; MRPL13 forward 5'-CCACAATGACACCAGAATAC-3' MRPL13 reverse, 5'-GAAGCCAACAGGACAGATA-3'.

Real-time PCR was then performed for each sample using the Human Tumor Metastasis RT ${ }^{2}$ Profiler TM PCR Array (No. 330231; Super Array Bioscience) in a Thermal Cycler Dice Real-Time System (Applied Biosystems ${ }^{\circledR}$ $7900 \mathrm{HT}$ ) according to the manufacturer's instructions. The data were normalized to the GAPDH levels using the $2^{-\Delta \Delta \mathrm{Ct}}$ method.

\section{Western Blotting}

The total protein fractions from tumor tissues and cultured cells were extracted using the Nuclear and Cytoplasmic Protein Extraction Kit (Beyotime, China). The protein concentrations were detected using the BCA protein assay kit (Beyotime, Haimen, China). Twenty-five micrograms of total nuclear protein was subjected to SDS-PAGE and then were electrotransferred onto PVDF membranes (Millipore, Billerica, MA, USA). After blocking with milk (5\%) for $2 \mathrm{~h}$, the membranes were incubated overnight at $4{ }^{\circ} \mathrm{C}$ with diluted (1:2000) primary antibodies as follows: polyclonal rabbit anti-MRPL13 (1:500, Novus Biologicals, NBP2-32572), polyclonal rabbit anti-MMP9 (Santa Cruz, 1:800), mouse monoclonal antibody against VEGFA (1:500; Santa Cruz Biotechnology, Santa Cruz, CA, USA), mouse monoclonal antibody against $M M P-2$ (1:500; Santa Cruz Biotechnology) and vinculin (keygen, China, 1:1000). Each corresponding secondary antibody was incubated at room temperature for 1 $\mathrm{h}$ at $37^{\circ} \mathrm{C}$. The protein bands were identified using an ECL system (Millipore, Bedford, MA, USA). The relative protein levels were calculated based on vinculin protein as a loading control.

\section{Cell Culture and RNA Transfection}

MRPL13-targeting siRNA-1 (sc-77761) and negative siRNA (sc-37007) were obtained from Santa Cruz Biotechnology, siRNA-2 was from the published literature: ${ }^{19}$ MRPL13 (5'-GUCUAGAUGAGUACACA CA and 5'-UGUGUGUACUCAUCUAGAC). Human BC cell lines (MCF-10A and MCF-7) were purchased from the American Type Culture Collection (Manassas, VA, USA). Both cell lines were plated at a density of $8 \times 10^{4}$ cells each per well in a 24-well plate and were maintained in RPMI 1640 medium (Gibco, USA) without antibiotics and supplemented with fetal bovine serum (FBS, HyClone, USA) for $24 \mathrm{~h}$ before the experiment. The cells were then transfected with MRPL13 siRNAs for 36 $\mathrm{h}$ using Lipofectamine LTX reagent (Invitrogen) according to the manufacturer's recommendation.

\section{Transwell Method to Detect Cell Invasion Activity}

For the invasion assay, polycarbonate filters were coated with $20 \mu \mathrm{L}$ of Matrigel (1:5; BD Bioscience) and placed in a Transwell Permeable chamber (Costar, USA). MCF-10A and MCF-7 cells were plated into 96-well plates at $4 \times 10^{4}$ cells $/ \mathrm{mL}$ for each well for the invasion assay; $1 \times 10^{5}$ cells were counted and suspended in $100 \mu \mathrm{L}$ of serum-free medium and then were added to the Transwell upper chamber (Costar, Corning, NY, USA) after transfection; Next, $600 \mu \mathrm{L}$ of complete medium (DMEM; Invitrogen; Thermo Fisher Scientific, Inc., Waltham, MA, USA) was added into the lower chamber. Following a 48-h incubation, the untransferred cells and Matrigel were removed using a cotton swab. The transfected cells were fixed using 4\% paraformaldehyde for $30 \mathrm{~min}$, permeabilized with $0.2 \%$ Triton X-100 (KeyGen, Nanjing, China) for $15 \mathrm{~min}$, and stained using $0.05 \%$ gentian violet (KeyGen) dye for $5 \mathrm{~min}$. The cells in five random regions were counted, and the average count was calculated. The experiment was performed in triplicate.

\section{Immune Infiltrate Analysis}

The TISIDB correlation module was used to evaluate potential relationships between MRPL13 expression and 
TIICs. The TISIDB database (http://cis.hku.hk/TISIDB/ index.php) uses the dataset information of currently published immunotherapy cohorts and existing literature reports. It is a useful website that provides a vast amount of tumor immunity-related data and is beneficial for comprehensive study of the interaction between tumors and immunity. First, the site manually compiled 4176 records from 2530 publications and includes 988 genes related to antitumor immunity. Second, this website analyzes highthroughput screening and genomic profiling data to identify genes that are related to the resistance or sensitivity of tumor cells to T-cell-mediated killing and immunotherapy. Third, the website precalculates the association between genes and immune functions (such as lymphocytes, immune modulators and chemokines) for 30 TCGA cancer types. The website uses ten analysis directions: function, literature, high-throughput screening, immunotherapy, tumor-infiltrating lymphocytes (TIL), immunomodulators, chemokines, subtypes, clinical and drugs. Additionally, to assess the relative variations in gene expression among the sample sets, we used a deconvolution algorithm based on gene expression called CIBERSORT (http://cibersort.stan ford.edu/). Using CIBERSORT, we measured the immune response of 22 TIICs to evaluate their association with MRPL13 expression in $\mathrm{BC}$ and to uncover correlations among TIICs. We used standard annotation files to establish gene expression datasets and used the default signature matrix at 1000 permutations. R software (including ggplot2, ggpubr, and ggExtra packages) was used to analyze the correlation between MRPL13 and immune checkpoints by TCGA data. To analyze the influence of MRPL13 on the microenvironment of the immune system, we utilized 846 tumor samples that we classified into 2 groups. To determine the types of lymphocytes affected by $M R P L 13$, we set up the p-value $<0.05$.

The human protein atlas database (HPA) (www.protei natlas.org) was used to analyze the protein expression of MRPL13 between normal and BC tissues. The HPA provides access to 32 human tissues and their protein expression profiles and uses antibody profiling to accurately assess protein localization. Additionally, the HPA provides measurements of RNA levels.

\section{Statistical Analysis}

All statistical analyses were conducted using R (Version 3.5.3). To calculate the $95 \%$ CI and HR, we used both univariate and multivariate models of Cox analysis. A P-value $<0.05$ for MRPL13 expression was set as the threshold. The correlations between the clinical characteristics and MRPL13 expression were analyzed using logistic regression. The correlations between MRPL13 and immune checkpoints were used Pearson test. In GSEA, gene sets with a false discovery rate (FDR) $<0.2$ were taken as significantly enriched gene sets.

\section{Results}

\section{Survival Outcomes and Variable Analysis}

The TCGA database was used to identify differences in the MRPL13 mRNA levels in normal and tumor tissues. In total, 1066 tumor files and 112 normal files were transformed to convert the count data to values more similar to those obtained from microarrays. The expression of MRPL13 in normal and BC samples was plotted on a boxplot (Figure 1A and B). Our analysis revealed the prevalence of MRPL13 expression in tumor tissues $\left(\mathrm{p}\right.$-value $\left.=2.2 \times 10^{-48}\right)$. Analysis of paired samples also revealed that MRPL13 is highly expressed in cancer tissues ( $\mathrm{P}$-value $=2.2 * 10^{-28}$; Figure $1 \mathrm{C}$ ). As shown in Table 1A, we used Cox analysis to explore connections between MRPL13 expression and OS, as well as other multivariable characteristics in $\mathrm{BC}$ patients. Univariate analysis of correlation revealed that some factors, including age $(\mathrm{HR}=1.034$; p-value $<0.001)$, pathological stage $(\mathrm{HR}=2.114 ;$ p-value $<0.001)$, tumor status $(\mathrm{T})$ $(\mathrm{HR}=1.456 ; \mathrm{p}$-value $<0.001)$, metastasis status $(\mathrm{M})$ $(\mathrm{HR}=6.523$; p-value $<0.001)$, node status $(\mathrm{N})(\mathrm{HR}=$ $1.700 ; \mathrm{p}$-value $<0.001)$ and $M R P L 13$ expression $(\mathrm{HR}=$ $1.040 ;$ p-value $<0.001)$ were significantly correlated with OS. The distribution of MRPL13 expression, survival status of patients with $\mathrm{BC}$, and expression profiles of MRPL13 are shown in Figure 1D. Our multivariate analysis, depicted as a forest boxplot in Figure 1E, revealed that MRPL13 expression ( $\mathrm{p}$-value $=0.002$ ) was an independent factor for prognosis (Table 1B). Tissue expression of MRPL13 protein was visualized using immunohistochemistry via HPA or Western blotting (Figure 1F-G).

\section{Relationship Between MRPLI3 Expression and Clinic Pathology}

The relationship between the MRPL13 expression levels and various clinicopathological parameters of $\mathrm{BC}$ patients was evaluated. TCGA contains $846 \mathrm{BC}$ samples including MRPL13 expression data obtained from patients with various clinical characteristics. Increased expression of 

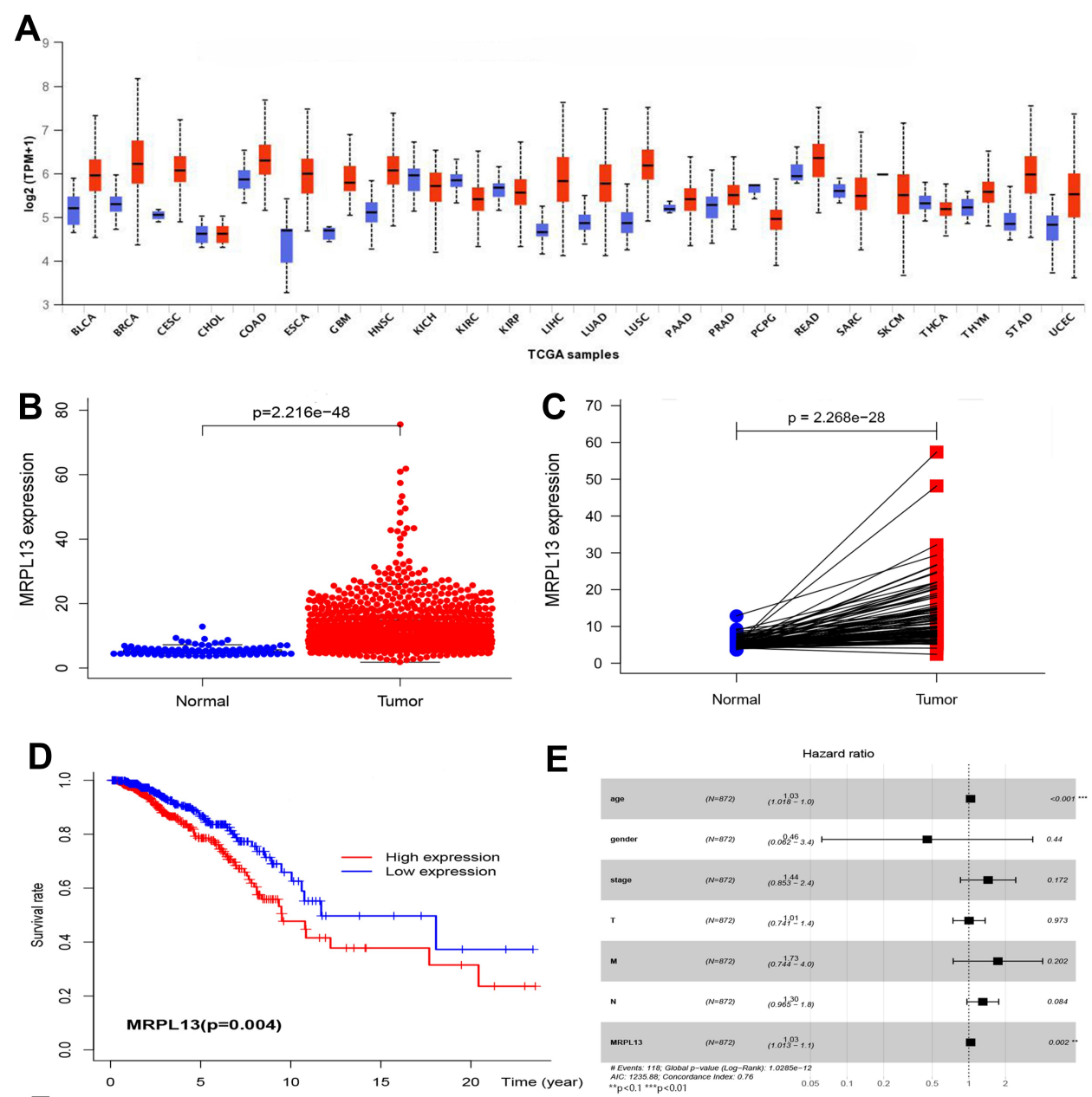

E

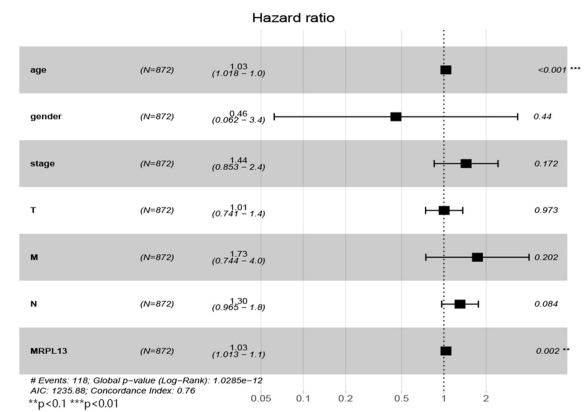

$\mathbf{F}$
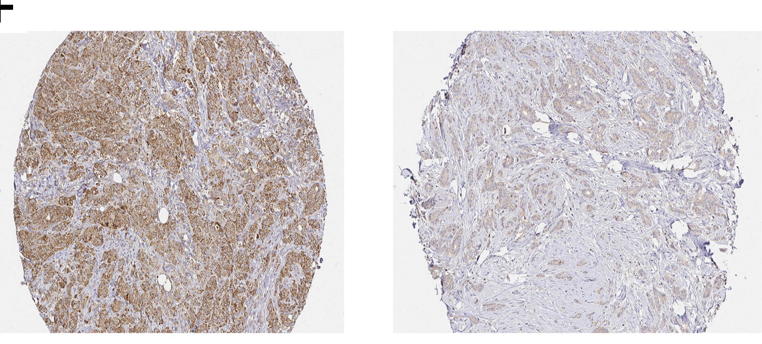

G

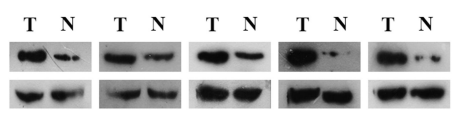

Figure I (A-C) Expression of MRPLI 3between normal and tumor tissues from the UALCAN website and TCGA database. (D) Levels of MRPLI3 mRNA expression and overall survival based on data obtained from TCGA. (E). Multivariate Cox analysis of MRPLI3 expression and other clinicopathological variables. (F-G) The expression of MRPLI3 protein was visualized using immunohistochemistry via HPA and analyzed by Western blotting.

MRPL13 was significantly correlated with cancer stage (p-value $<0.001$; Figure 2A), cancer subclass (p-value $<$ 0.001 ; Figure $2 \mathrm{~B}$ ) and nodal metastasis status (p-value $<$ 0.001; Figure 2C). From the UALCAN website (http:// ualcan.path.uab.edu/analysis.html), univariate analysis uncovered a correlation between MRPL13 expression and poor clinicopathological and prognostic characteristics. Increased MRPL13 expression levels in BC were significantly correlated with the tumor status (III vs I; p-value = 0.019 ), stage (III vs I; p-value $=0.010$ ), grade (II vs I, $\mathrm{p}$-value $=0.020 ;$ III vs I, p-value $=0.000 ;$ IV vs I, p-value
$=0.002)$, and patient age $(\mathrm{p}$-value $=0.014)$. These results suggest that $\mathrm{BC}$ patients with high levels of MRPL13 expression are more prone to have tumors that are more advanced in the nodal metastasis status, cancer subclass and cancer stage than those with low levels of MRPL13 expression (Table 2).

\section{GSEA Investigation of MRPLI3}

GO, KEGG pathway and immunologic analyses were performed to explore the potential biological functions of MRPL13. GSEA revealed significant differences (NOM 
Table I Correlation Between Overall Survival and Multivariable Characteristics in TCGA Patients via (a) Cox Regression (b) Multivariate Survival Model

\begin{tabular}{|c|c|c|c|c|c|c|c|}
\hline \multicolumn{8}{|c|}{ (a) Cox Regression } \\
\hline ID & $H R$ & \multicolumn{2}{|c|}{ HR.95L } & \multicolumn{2}{|c|}{ HR.95H } & \multicolumn{2}{|c|}{$P$ value } \\
\hline Age & 1.034 & \multicolumn{2}{|c|}{1.019} & \multicolumn{2}{|c|}{1.049} & \multicolumn{2}{|c|}{$7.11 \mathrm{E}-06^{*}$} \\
\hline Gender & 0.886 & \multicolumn{2}{|c|}{0.123} & \multicolumn{2}{|c|}{6.362} & \multicolumn{2}{|c|}{0.904518} \\
\hline Stage & 2.114 & \multicolumn{2}{|c|}{1.662} & \multicolumn{2}{|c|}{2.688} & \multicolumn{2}{|c|}{ I.03E-09* } \\
\hline $\mathrm{T}$ & 1.456 & \multicolumn{2}{|c|}{1.165} & \multicolumn{2}{|c|}{1.821} & \multicolumn{2}{|c|}{$0.000955^{*}$} \\
\hline M & 6.523 & \multicolumn{2}{|c|}{3.651} & \multicolumn{2}{|c|}{11.65} & \multicolumn{2}{|c|}{$2.38 \mathrm{E}-10 *$} \\
\hline$N$ & 1.700 & \multicolumn{2}{|c|}{1.405} & \multicolumn{2}{|c|}{2.056} & \multicolumn{2}{|c|}{$4.66 \mathrm{E}-08^{*}$} \\
\hline MRPLI3 & 1.040 & \multicolumn{2}{|c|}{1.019} & \multicolumn{2}{|c|}{1.061} & \multicolumn{2}{|c|}{$0.000143 *$} \\
\hline \multicolumn{8}{|c|}{ (b) Multivariate survival model } \\
\hline ID & \multicolumn{2}{|c|}{$\mathrm{HR}$} & \multicolumn{2}{|c|}{ HR.95L } & $H R$ & $95 \mathrm{H}$ & $P$ value \\
\hline Age & & 33 & 1.0 & & 1.0 & & 2.13E-05* \\
\hline Gender & & 55 & 0.0 & & 3.3 & & 0.440 \\
\hline Stage & & 140 & 0.8 & & 2.4 & & 0.17188 \\
\hline $\mathrm{T}$ & & 05 & 0.7 & & 1.3 & & 0.973314 \\
\hline M & & 34 & 0.7 & & 4.0 & & 0.201902 \\
\hline$N$ & & 03 & 0.9 & & 1.7 & & 0.084406 \\
\hline MRPLI3 & & 34 & 1.0 & & 1.0 & & $0.00165^{*}$ \\
\hline
\end{tabular}

Note: $* \mathrm{P}<0.05$.

p-value $<0.050$ ) in the enrichment of GO terms, KEGG pathways and immunologic signatures in samples with high levels of MRPL13. We selected the most highly enriched signaling pathways based on their normalized enrichment score (NES).

As shown in Table 3, GO annotation revealed five categories that were positively correlated with high levels of MRPL13: regulation of cell migration involved in sprouting angiogenesis, regulation of smoothened signaling pathway, cellular response to vascular endothelial growth factor stimulus, smooth muscle cell migration, and positive regulation of endothelial cell migration. GO analysis also uncovered five negatively correlated categories: meiotic cell cycle process, mitochondrial translation, negative regulation of cell cycle $\mathrm{G} 2 \mathrm{~m}$ phase transition, ribosomal small subunit biogenesis and negative regulation of nuclear division. The biological processes and molecular functions strongly associated with MRPL13 were cell migration, angiogenesis and smoothened signaling pathway (Figure 2D).

KEGG pathway analysis showed five pathways that had the strongest positive correlation with MRPL13 expression: ECM receptor interaction, vascular smooth muscle contraction, notch signaling pathway, MAPK signaling pathway, and hedgehog signaling pathway. The five pathways with the strongest negative correlation were cell cycle, RNA degradation, RNA polymerase, DNA replication and basal transcription factors (Figure 2E). These results indicate that the pathways regulating cell cycle RNA degradation and DNA replication, which are critically important in $\mathrm{BC}$ patients, were strongly associated with MRPL13 expression.

Immunologic signature analysis showed five pathways that had the strongest positive correlation with MRPL13 expression: IL12 and TGFB ACT vs ACT CD4 T cell $6 \mathrm{~h}$ up, UNSTIM vs IL15 stim NKCELL up, cent memory CD4 T cell vs TH1 up, unstim vs FCGRIIB stim monocyte $\mathrm{dn}$, and memory CD4 T cell vs TH1 up. The five pathways with the strongest negative correlation were naive vs 24 $h$ in vitro stim infab CD8 $\mathrm{T}$ cell $\mathrm{dn}$, brain vs colon tumoral macrophage dn, SOCS3 KO vs wt liver up, ctrl vs ACT IL4 and anti IL12 $24 \mathrm{~h}$ CD4 T cell dn, ctrl vs ACT IL4 and anti IL12 $12 \mathrm{~h} \mathrm{CD} 4 \mathrm{~T}$ cell dn (Figure 2F). These results indicate that the pathways regulating $\mathrm{CD} 4+, \mathrm{CD} 8+$ and macrophage expression, which are critically important in $\mathrm{BC}$ patients, are strongly associated with MRPL13 expression.

\section{MRPLI 3 Regulates MMPs and VEGFA Expression in BC Cells}

To determine whether higher levels of MRPL13 contributed to the invasion of $\mathrm{BC}$ cells, we employed siRNA to knock down MRPL13 expression in MCF-10A and MCF-7 cancer cell lines. MRPL13 expression was unaffected by transient transfection of negative siRNA (Neg. siRNA), whereas MRPL13-specific siRNA-1 (MRPL13 siRNA) considerably reduced the mRNA and protein expression levels $36 \mathrm{~h}$ after siRNA treatment (data not shown). As shown in Figure 3, MRPL13 knockdown blocked BC cell invasion using the Matrigel invasion assay.

To obtain further insight into the functions of MRPL13 in $\mathrm{BC}$ cell invasion and metastasis, the mRNA expression profile of siMRPL13-transfected MCF-10A cells was compared with that of Neg. siRNA-transfected cells using a Human Tumor Metastasis RT2 Profiler ${ }^{\mathrm{TM}}$ PCR Array containing 84 cell metastasis-related genes. Four upregulated genes and six downregulated genes (at least 2-fold) were identified in MRPL13 siRNA-transfected MCF-10A cells but not in Neg. siRNA-transfected controls (Supplementary Table S1). Subsequently, MMP2, MMP9 and VEGFA, which showed the greatest fold change (3-fold) after MRPL13 knockdown, were selected and 
A

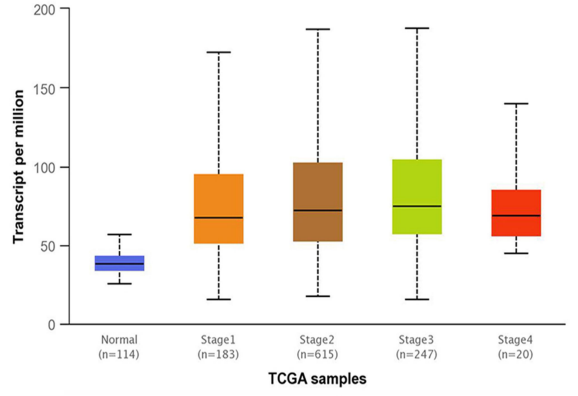

B

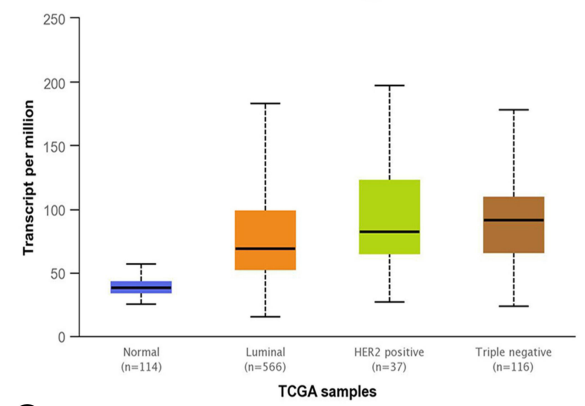

C

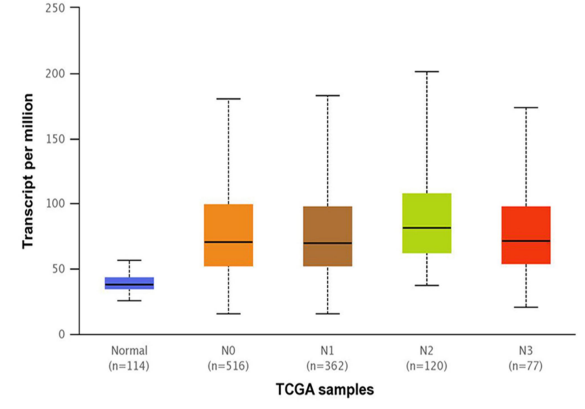

D

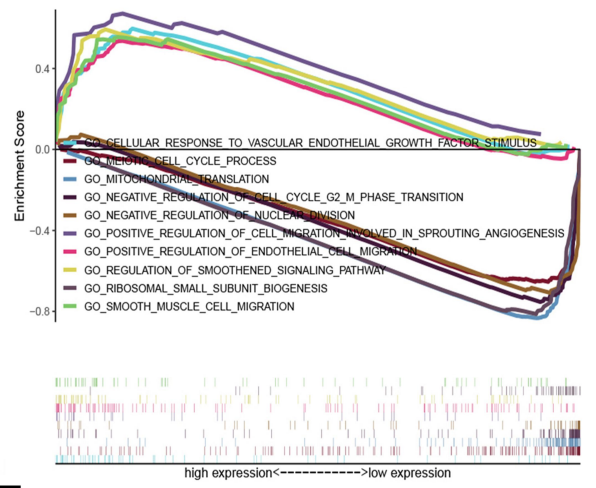

E
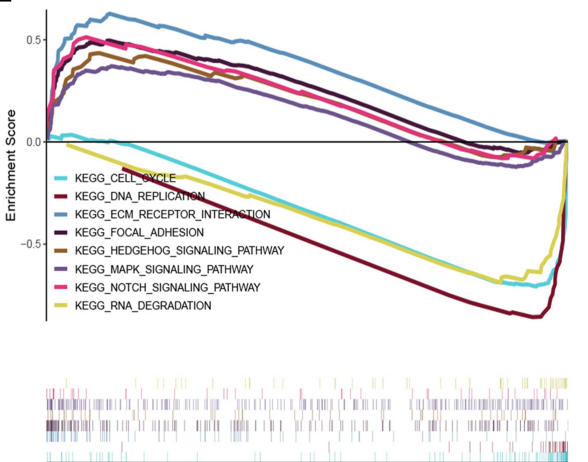

high expression<---------->low expressio

$\mathbf{F}$
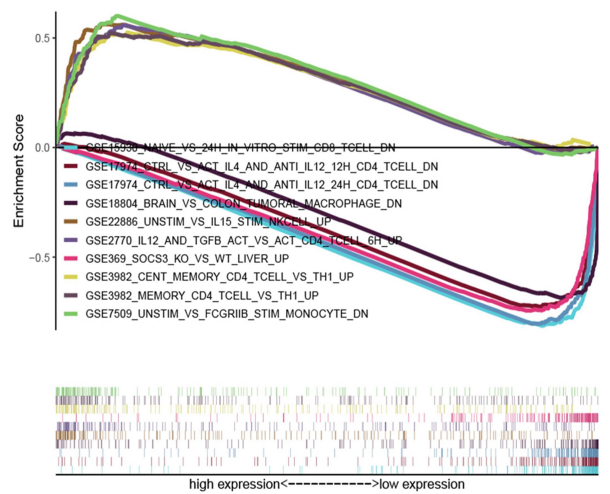

Figure 2 (A) MRPLI 3 expression is correlated significantly with cancer stage, (B) cancer subclass histological grade (C) and nodal metastasis status. (D) The KEGG pathway showed five positively correlated groups and five negatively correlated groups. (E) GO term analysis revealed five positively correlated groups and five negatively correlated groups. (F) Immunologic signatures pathway showed five positively correlated groups and five negatively correlated groups.

evaluated by Western blot analysis. We observe remarkable changes in their expression (Figure 3).

\section{Relationship Between MRPLI3}

\section{Expression and Tumor-Infiltrating Immune Cells}

Independent tumor-infiltrating lymphocytes play a key role in the prediction of the overall survival rate and sentinel lymph node status. Therefore, we used TISIDB to analyze possible correlations between MRPL13 expression and the levels of immune infiltration in BC. MRPL13 expression showed a positive correlation with the levels of active_CD4 + (Act_CD4+; p-value $=1.2 \times 10^{-17}$ ), active_CD8+ (Act_CD8+; p-value $=7.5 \times 10^{-9}$ ), active dendritic cells $\left(\right.$ Act DC; $p$-value $\left.=1.3 \times 10^{-5}\right)$ and Tgd cells $(\mathrm{p}$-value $=$ $1.03 \times 10^{-5}$ ): negative correlation with the levels of NK cells $\left(\mathrm{p}\right.$-value $\left.=2.1 \times 10^{-22}\right)$, neutrophil cells $(\mathrm{p}$-value $<2.2 \times$ $10^{-16}$ ) and active $\mathrm{B}$ cells $\left(\mathrm{p}\right.$-value $=4.05 \times 10^{-8}$ ) 
Table 2 Association Between MRPL/3 Expression and Clinicopathological Characteristics from UALCAN Website

\begin{tabular}{|l|l|}
\hline Comparison & Statistical Significance \\
\hline Nodal metastasis status & \\
Normal-vs-N0 & $1.62 \mathrm{E}-12$ \\
Normal-vs-NI & $\mathrm{I} .62 \mathrm{E}-12$ \\
Normal-vs-N2 & $4.38 \mathrm{E}-07$ \\
Normal-vs-N3 & $2.95 \mathrm{E}-12$ \\
N0-vs-NI & $9.77 \mathrm{E}-0 \mathrm{I}$ \\
N0-vs-N2 & $4.72 \mathrm{E}-02$ \\
N0-vs-N3 & $8.68 \mathrm{E}-0 \mathrm{I}$ \\
NI-vs-N2 & $4.78 \mathrm{E}-02$ \\
\hline Cancer subclasses & \\
Normal-vs-Luminal & $<1 \mathrm{E}-12$ \\
Normal-vs-HER2 Positive & $3.42 \mathrm{E}-07$ \\
Normal-vs-TNBC & $<1 \mathrm{E}-12$ \\
\hline Cancer stages & \\
Normal-vs-Stagel & $\mathrm{I} .62 \mathrm{E}-\mathrm{I} 2$ \\
Normal-vs-Stage2 & $<1 \mathrm{E}-12$ \\
Normal-vs-Stage3 & $2.74 \mathrm{E}-14$ \\
Normal-vs-Stage4 & $2.24 \mathrm{E}-03$ \\
Stagel-vs-Stage3 & $3.83 \mathrm{E}-02$ \\
\hline
\end{tabular}

(Figure 4A). These results indicate that MRPL13 plays a key role in immune infiltration in BC. Additionally, the correlation between MRPL13 and commonly used immune checkpoints (CTLA4, PD-L1, LAG3, TIM3) were analyzed, the results indicated that $M R P L 13$ was positively correlated with CTLA4 $\left(\mathrm{R}=0.15, \mathrm{p}\right.$-value $\left.=5.0 \times 10^{-7}\right)$, LAG3 $\left(\mathrm{R}=0.21, \mathrm{p}\right.$-value $\left.=1.2 \times 10^{-13}\right)$ and $\operatorname{TIM} 3(\mathrm{R}=0.058$, $\mathrm{p}$-value $=0.045)($ Figure 4B). Moreover, we tried to determine whether the tumor immune microenvironment was different in $\mathrm{BC}$ patients with high MRPL13 levels compared with that in BC patients with low MRPL13 levels. The 846 tumor samples were divided into 2 groups based on MRPL13 expression, with 423 samples in the high expression group and 423 samples in the low expression group. We used an established computational resource, CIBERSORT, to explore the gene expression profiles of downloaded samples to determine the levels of 22 types of immune cells. The CIBERSORT algorithm applied to the 22 immune cell subtypes helped to assess differences in their expression levels in the high and low MRPL13 expression groups (Figure 4C). Resting CD4 memory T cells, activated resting CD4 memory $\mathrm{T}$ cells, follicular helper $\mathrm{T}$ cells, monocytes, M0 macrophages, M1 macrophages and resting mast cells were affected by MRPL13 expression between the high and low MRPL13 groups. Compared with the low expression group,
M0/M1 macrophages, T cells CD4 memory activated and $\mathrm{T}$ cells follicular helper were increased (p-value $<0.001)$ in the high expression group, whereas resting CD4 memory $T$ cells, $B$ cells naive and resting mast cells were decreased (p-value $<0.05$ ). We also assessed possible correlations among the 22 types of immune cells, the resulting heat map revealed that the ratios of different tumor-infiltrating immune cell subpopulations were weakly to moderately correlated (Figure 4D).

\section{Discussion}

In this study, the TCGA database and multiple online analysis tools were used to analyze the mRNA and protein expression levels of MRPL13 in BC tissues and adjacent tissues, the expression levels of MRPL13 mRNA in different BC stages, and the correlation between MRPL13 mRNA and patient prognosis. Gene expression profiling, immunohistochemistry, and WB results showed that $\mathrm{BC}$ tissues highly expressed MRPL13 compared with adjacent tissues. Cancer subclasses were different from normal tissues, but no significant difference was found between different subclasses. Cancer stage analysis found significant differences in stage 1 vs stage 3, suggesting that MRPL13 expression is related to $\mathrm{BC}$ progression. MRPL13 expression was significantly related to overall survival, which was significantly lower in patients with high expression than in those with low expression (P $<0.001)$. In summary, MRPL13 is an important molecule to promote $\mathrm{BC}$ progression and may be a target for $\mathrm{BC}$ treatment as previous studies. $^{20}$

Through pathway enrichment analysis, we found that MRPL13 participates in pathways such as regulation of cell migration, positive regulation of endothelial cell migration, notch signaling pathway, and MAPK signaling pathway. Through cell invasion experiments, we confirmed that interference with $\mathrm{BC}$ cell invasion was decreased after interference with MRPL13 expression. Additionally, further study by PCR leads to the question of how MRPL13 promotes $\mathrm{BC}$ progression. Invasion experiments demonstrated that inhibition of MRPL13 expression reduces the invasive ability of $\mathrm{BC}$ cells. Additionally, MRPL13 knockdown decreases VEGFA, $M M P-2$, and $M M P-9$ expression. $V E G F$ can stimulate the proliferation of vascular endothelial cells and increase vascular permeability. It is also considered one of the main mediators of angiogenesis that plays a key role in tumor progression. In the early stage of hypoxia, cancer 
Table 3 Signaling Pathways (KEGG, GO, Immunologic Signatures) Most Significantly Correlated with MRPLI 3 Expression Based on Their Normalized Enrichment Score (NES) and p-value

\begin{tabular}{|c|c|c|c|c|}
\hline GO Ana & & & & \\
\hline Positive & $\begin{array}{l}\text { NAME } \\
\text { GO POSITIVE REGULATION OF CELL MIGRATION INVOLVED IN } \\
\text { SPROUTING ANGIOGENESIS } \\
\text { GO REGULATION OF SMOOTHENED SIGNALING PATHWAY } \\
\text { GO CELLULAR RESPONSE TO VASCULAR ENDOTHELIAL GROWTH } \\
\text { FACTOR STIMULUS } \\
\text { GO SMOOTH MUSCLE CELL MIGRATION } \\
\text { GO POSITIVE REGULATION OF ENDOTHELIAL CELL MIGRATION } \\
\text { NAME }\end{array}$ & $\begin{array}{l}\text { NES } \\
2.152 \\
2.132 \\
2.096 \\
2.081 \\
2.065 \\
\text { NES }\end{array}$ & $\begin{array}{l}\text { NOM p-val } \\
0 \\
0.0019 \\
0.0018 \\
0 \\
0 \\
\text { NOM p-val }\end{array}$ & $\begin{array}{l}\text { FDR q-val } \\
0.046 \\
0.043 \\
0.039 \\
0.042 \\
0.042 \\
\text { FDR q-val }\end{array}$ \\
\hline Negative & $\begin{array}{l}\text { GO MEIOTIC CELL CYCLE PROCESS } \\
\text { GO MITOCHONDRIAL TRANSLATION } \\
\text { GO NEGATIVE REGULATION OF CELL CYCLE G2 M PHASE TRANSITION } \\
\text { GO RIBOSOMAL SMALL SUBUNIT BIOGENESIS } \\
\text { GO NEGATIVE REGULATION OF NUCLEAR DIVISION }\end{array}$ & $\begin{array}{l}-2.617 \\
-2.582 \\
-2.518 \\
-2.501 \\
-2.495\end{array}$ & $\begin{array}{l}0 \\
0 \\
0 \\
0 \\
0\end{array}$ & $\begin{array}{l}0 \\
0 \\
5.84 \mathrm{E}-05 \\
3.55 \mathrm{E}-05 \\
3.31 \mathrm{E}-05\end{array}$ \\
\hline \multicolumn{5}{|c|}{ KEGG analysis } \\
\hline Positive & $\begin{array}{l}\text { NAME } \\
\text { KEGG ECM RECEPTOR INTERACTION } \\
\text { KEGG VASCULAR SMOOTH MUSCLE CONTRACTION } \\
\text { KEGG NOTCH SIGNALING PATHWAY } \\
\text { KEGG MAPK SIGNALING PATHWAY } \\
\text { KEGG HEDGEHOG SIGNALING PATHWAY }\end{array}$ & $\begin{array}{l}\text { NES } \\
1.961 \\
1.614 \\
1.712 \\
1.583 \\
1.639\end{array}$ & $\begin{array}{l}\text { NOM p-val } \\
0.0039 \\
0.0152 \\
0.0165 \\
0.0168 \\
0.0205\end{array}$ & $\begin{array}{l}\text { FDR q-val } \\
0.201 \\
0.252 \\
0.346 \\
0.230 \\
0.314\end{array}$ \\
\hline Negative & $\begin{array}{l}\text { NAME } \\
\text { KEGG CELL CYCLE } \\
\text { KEGG RNA DEGRADATION } \\
\text { KEGG RNA POLYMERASE } \\
\text { KEGG DNA REPLICATION } \\
\text { KEGG BASAL TRANSCRIPTION FACTORS }\end{array}$ & $\begin{array}{l}\text { NES } \\
-2.438 \\
-2.405 \\
-2.231 \\
-2.235 \\
-2.187\end{array}$ & $\begin{array}{l}\text { NOM p-val } \\
0 \\
0 \\
0 \\
0 \\
0.0019\end{array}$ & $\begin{array}{l}\text { FDR q-val } \\
0 \\
0 \\
9.78 \mathrm{E}-04 \\
0.001 \\
0.001\end{array}$ \\
\hline \multicolumn{5}{|c|}{ Immunologic signature } \\
\hline Positive & $\begin{array}{l}\text { NAME } \\
\text { GSE2770 ILI2 AND TGFB ACT VS ACT CD4 TCELL 6H UP } \\
\text { GSE22886 UNSTIM VS ILI5 STIM NKCELL UP } \\
\text { GSE3982 CENT MEMORY CD4 TCELL VS THI UP } \\
\text { GSE7509 UNSTIM VS FCGRIIB STIM MONOCYTE DN } \\
\text { GSE3982 MEMORY CD4 TCELL VS THI UP }\end{array}$ & $\begin{array}{l}\text { NES } \\
2.276 \\
2.274 \\
2.194 \\
2.192 \\
2.130\end{array}$ & $\begin{array}{l}\text { NOM p-val } \\
0 \\
0 \\
0 \\
0 \\
0\end{array}$ & $\begin{array}{l}\text { FDR q-val } \\
0.028 \\
0.019 \\
0.044 \\
0.036 \\
0.0312\end{array}$ \\
\hline Negative & $\begin{array}{l}\text { NAME } \\
\text { GSEI5930 NAIVE VS } 24 \mathrm{H} \text { IN VITRO STIM INFAB CD8 TCELL DN } \\
\text { GSEI8804 BRAIN VS COLON TUMORAL MACROPHAGE DN } \\
\text { GSE369 SOCS3 KO VS WT LIVER UP } \\
\text { GSEI7974 CTRL VS ACT IL4 AND ANTI ILI2 24H CD4 TCELL DN } \\
\text { GSEI7974 CTRL VS ACT IL4 AND ANTI ILI2 I2H CD4 TCELL DN }\end{array}$ & $\begin{array}{l}\text { NES } \\
-2.747 \\
-2.732 \\
-2.722 \\
-2.703 \\
-2.701\end{array}$ & $\begin{array}{l}\text { NOM p-val } \\
0 \\
0 \\
0 \\
0 \\
0\end{array}$ & $\begin{array}{l}\text { FDR q-val } \\
0 \\
0 \\
0 \\
0 \\
0\end{array}$ \\
\hline
\end{tabular}

cells activate multiple signaling pathways to produce multiple $V E G F s$, promoting the proliferation of endothelial cells and forming new vascular endothelial cells. ${ }^{21,22}$ The higher expression of VEGFAis closely related to tumor micro vessel density, tumor recurrence and metastasis, as well as the poor prognosis of patients. $^{23,24}$ Silencing VEGFA in BC can significantly inhibit cancer angiogenesis and metastasis. ${ }^{25,26}$ Therefore, anti-VEGF therapies, such as the anti-VEGF antibody bevacizumab, have been widely used clinically 

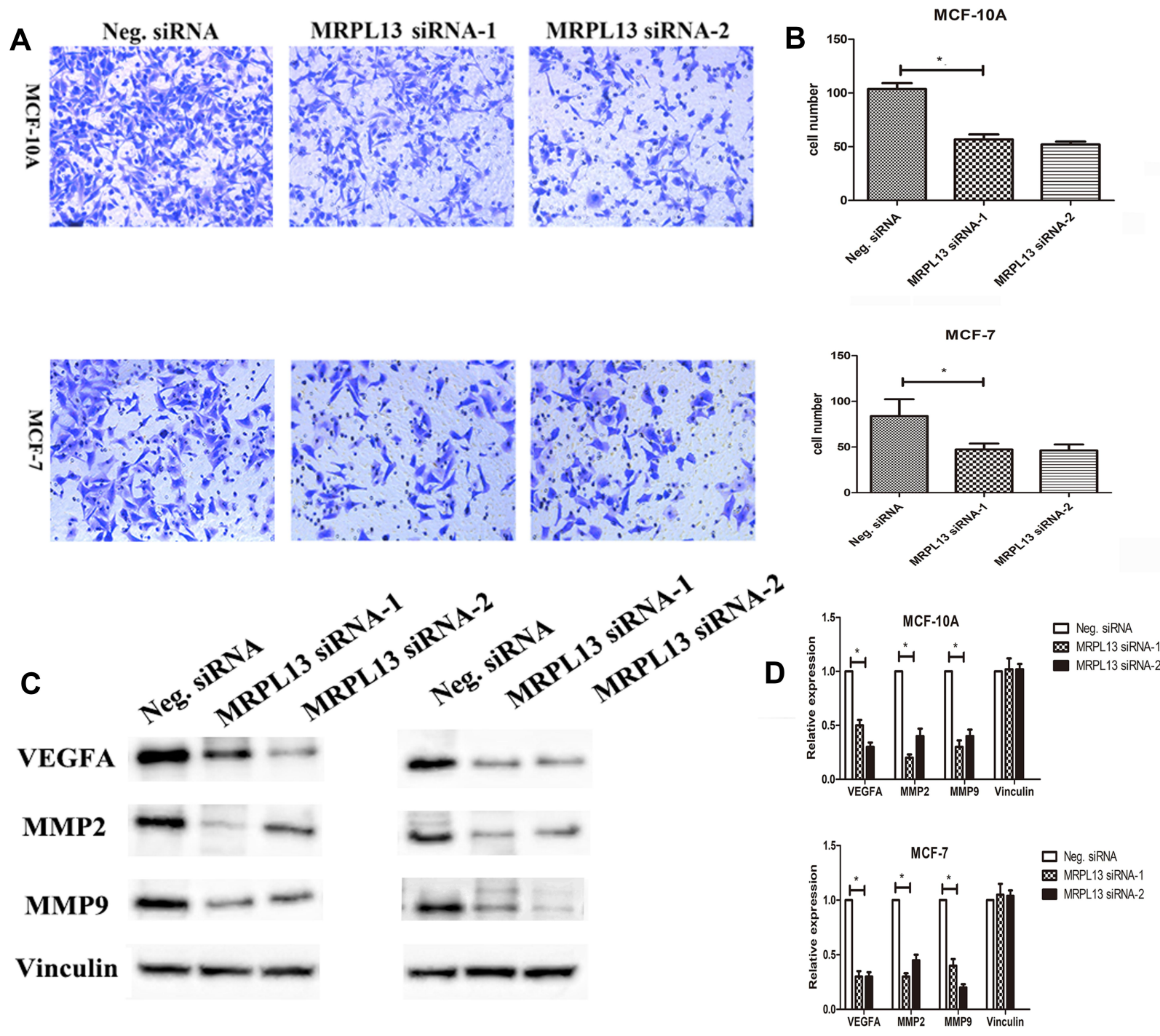

Figure 3 Invasion assays of MCF-10A and MCF-7 cells transfected with Neg. siRNA and MRPLI3 siRNA. The MRPLI 3 siRNA group showed a measurable blocking effect on cell invasion in both cell lines. The numbers of cells invading into the lower surface of the filter were counted, and a significant difference was observed $(\mathbf{A}, \mathbf{B} ; * \mathrm{P}<0.05)$. Columns, mean; bars, SD; Expression of vascular endothelial growth factor A (VEGFA), matrix metalloproteinase 2 (MMP-2), and MMP-9in MRPL $13-$ depleted MCF-10A and MCF-7 cells. (C) Western blotting and (D) real-time PCR analysis showed the expression changes after silencing MRPLI3 in MCF-IOA and MCF-7 cells. The expression levels of VEGFA, MMP-2, and MMP-9 were explored. (Columns, mean; bars, SD. *P < 0.05).

and have improved the survival of some patients. ${ }^{27}$ Matrix metalloproteinases are well known to play an important role in ECM degradation, tumor cell invasion and metastasis. ${ }^{28}$ Matrix metalloproteinase $2(M M P-2)$ and $M M P-9$ have been reported to promote invasion and tumorigenesis in different cancer cells and are correlated with metastasis and poor patient prognosis in lung cancer, colorectal cancer, and prostate cancer. ${ }^{29-31}$ Thus, $M R P L 13$ expression may affect $\mathrm{BC}$ progression through its effect on MMPs. We examined VEGFA, MMP-2 and $M M P-9$ expression before and after siRNA transfection. The result showed that MRPL13 significantly affects invasiveness by changing $M M P$ expression.
During tumor development, immune cells in the tumor microenvironment (TME) infiltrate and secrete inflammatory mediators, forming an inflammatory microenvironment, which can assist tumor immune escape and distant metastasis as the tumor progresses. ${ }^{32,33}$ In most patients with solid tumors, abnormal blood vessels can help the tumor escape the immune system. ${ }^{34,35}$ First, the leakage of tumor blood vessels and disturbance of lymphatic drainage function will lead to an increase in TME interstitial fluid pressure, but tumor cells can overcome these conditions to obtain a stronger survival advantage. ${ }^{36}$ Abnormal blood vessels and damaged perfusion can also limit cytotoxic drugs and immune cells from circulating the tumor, 

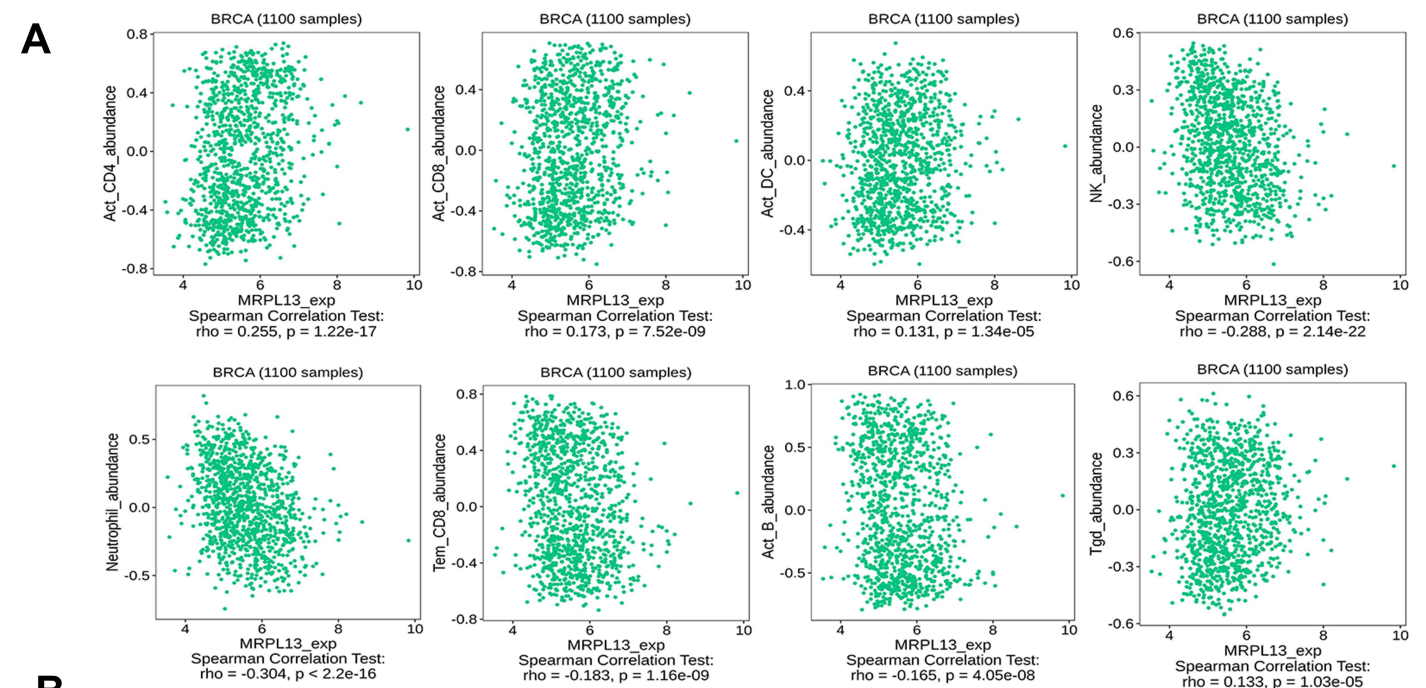

B
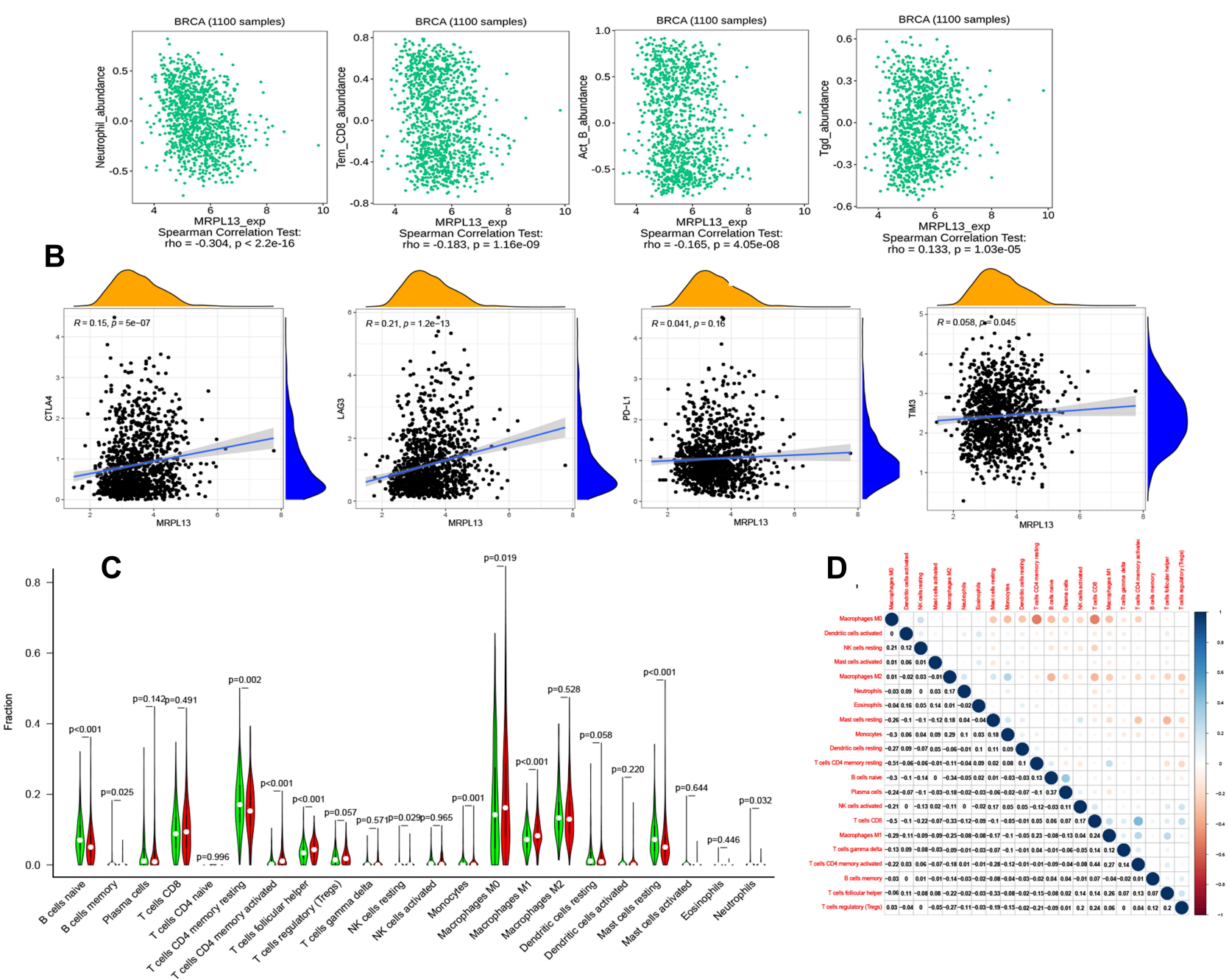

Figure 4 (A) Correlation between MRPLI3 expression and immune infiltration levels from the TISIDB website (http://cis.hku.hk/TISIDB/index.php). (B) The correlation between MRPLI 3 and immune checkpoint molecules (PD-LI, CTLA4, TIM3 and LAG3). (C) Different proportions of 22 subtypes of immune cells in the high and low MRPLI3 expression groups in TCGA BC samples. (D) Heatmap of 22 immune infiltration cells in tumor samples.

thereby limiting their anticancer activity. In addition, abnormally leaking blood vessels can promote the shedding of cancer cells into the blood. ${ }^{37,38}$ After entering the systemic circulation, some tumor cells can spread to distant organs and form metastatic tumors. The infiltration of cytokines such as $V E G F$ from the TME into the systemic circulation can also enhance the outflow and metastasis of metastatic cancer cells from blood vessels to distant organs. $^{39,40}$ By contrast, although $\mathrm{CD} 8+$ cytotoxic
T lymphocytes (CTLs) can also colonize tumors, various factors in the TME often make these cells dysfunctional or restrict their entry into tumors. ${ }^{41}$ Therefore, drugs targeting these $V E G F$ molecules can improve the response of immunotherapy, normalize the abnormal tumor vascular system, and increase the infiltration of immune effector cells. $^{42}$ When we found that MRPL13 is involved in the enrichment of vascular endothelial metastasis, we further analyzed the expression of immune-infiltrating cells. 
Classical immunohistochemical analysis relies on a marker to identify a specific immune cell subgroup, cannot identify more subgroups and performs poorly in capturing certain cell phenotypes, such as activated and inactivated lymphocytes. Therefore, we used CIBERSORT to infer the proportion of the 22 immune cell subpopulations from transcriptome data and used gene expression profiles to assess the relative proportions of different immune cell subpopulations. At the same time, by searching the data from the TISIDB website, we further enriched our research results, which revealed a systematic difference between theMRPL13 expression and infiltration levels of immune cell macrophages and mast cells. Our findings showed that M0/M1 macrophages were found at increased levels in the high MRPL13 expression group, whereas levels of NK cells and mast cells were decreased from TISIDB data. NK cells, as an important part of the body's innate immune system, play a major role in the immune surveillance of BC. ${ }^{43}$ The activity of NK cells in BC patients is significantly decreased, the expression of surface receptors is altered, and the expression of activated receptors is limited. ${ }^{44}$ Additionally, inhibitory receptor levels are significantly elevated. In vitro and in vivo studies have found that ${ }^{131}$ I treatment can enhance the cytotoxicity of NK cells to $\mathrm{BC}$ cells, can increase the level of $\mathrm{BC}$ cell death receptors, and can enhance NK cell treatment by enhancing the cytotoxicity of NK cells to tumor cells. ${ }^{44,45}$ Our results indicate a possible mechanism where MRPL13 regulates the functions of NK cells in BC. However, controlled trials and multicenter clinical trials are required to more accurately understand the relationship between MRPL13 and NK cells in vivo.

Immune checkpoint molecules are regulatory molecules, which inhibit the function of immune cells and suppress the anti-tumor immune response in immune system, and eventually lead to immune escape. ${ }^{46}$ The main immune checkpoint molecules related to tumors are: $P D 1 /$ PD-L1, CTLA4, TIM3 and LAG3. ${ }^{47}$ Immune checkpoint inhibitors are a class of monoclonal antibodies developed for the related immune checkpoints. Its main function is to block the connection between tumor cells and immune cells that expressing immune checkpoints, thereby relieves the inhibitory effect and allows immune cells to kill cancer cells. $^{48}$

CTLA4, also known as CD152, is expressed on activated $\mathrm{CD} 4+$ and $\mathrm{CD} 8+\mathrm{T}$ cells and has a high degree of homology with the costimulatory molecule receptor (CD28) on the surface of T cells. ${ }^{49}$ Both CTLA-4 and
$C D 28$ are members of the immunoglobulin superfamily, which bind to the same ligands $C D 86$ (B7-2) and $C D 80$ (B7-1). When the two signals B7-CD28 and B7-CTLA4 are activated at the same time, $\mathrm{T}$ cells can be activated and expressed CTLA-4. CTLA4 forms a competitive relationship with $C D 28$, and when combined with $B 7$, it blocks the $B 7-C D 28$ signaling pathway. ${ }^{50}$ Cancer cells take advantage of the negative regulation of the human immune system to promote the expression of CTLA4 and compete with $C D 28$ to achieve the goal of survival. CTLA4 antibody binds to CTLA4, CD28 can bind to B7 again, the $B 7-C D 28$ signal channel is restarted, and T cells are activated. ${ }^{51}$

From Figure 4, MRPL13, positively correlated with CTLA4, is differentially expressed with T cells CD4 memory activated, $\mathrm{T}$ cells follicular helper and other cells. This result suggests whether we can participate in the immune checkpoint by inhibiting the expression of MRPL13. Could regulation predict the response to immune checkpoint blockade? Could it be used as an effective immune checkpoint blockade combination therapy to increase efficacy and reduce side effects? A variety of methods were used to avoid immune elimination, so a better understanding of the immune suppression in tumor microenvironment is our future focus.

In conclusion, this is the first report to identify MRPL13 as a new biomarker of BC. This work helps to elucidate the roles of cytokinesis and immune cell infiltration, as well as the proteins that regulate these processes, in the development of BC. With a better understanding of its functional range, MRPL13 could serve as an effective tool for the diagnosis and treatment of $\mathrm{BC}$ and may help to make biomarker therapies a promising option for the treatment of breast diseases.

\section{Data Sharing Statement}

The dataset used and/or analyzed during the current study are available from the corresponding author Zuo Tao (taozuocmu@163.com) on reasonable request.

\section{Acknowledgments}

We thank all participating subjects for their kind cooperation in this study.

\section{Disclosure}

The authors declare that they have no competing interests. 


\section{References}

1. Fahad Ullah M. Breast Cancer: current Perspectives on the Disease Status. Adv Exp Med Biol. 2019;1152:51-64.

2. Heger Z, Rodrigo MA, Krizkova S, Zitka O, Beklova M. Kizek $\mathrm{R}$ and Adam $\mathrm{V}$. Identification of estrogen receptor proteins in breast cancer cells using matrix-assisted laser desorption/ionization time of flight mass spectrometry (Review). Oncol Lett. 2014;7(5):13 41-1344. doi:10.3892/ol.2014.1912

3. Hortobagyi GN, Chen D, Piccart M, et al. Correlative Analysis of Genetic Alterations and Everolimus Benefit in Hormone Receptor-Positive, Human Epidermal Growth Factor Receptor 2-Negative Advanced Breast Cancer: results From BOLERO-2. $J$ Clin Oncol. 2016;34(5):419-426. doi:10.1200/JCO.2014.60.1 971

4. Ragazzi M, Bisagni A, Gasparini E, et al. Bisagni G and Gardini G. Impact of 2013 ASCO/CAP guidelines on HER2 determination of invasive breast cancer: A single institution experience using frontline dual-color FISH. Breast. 2017;34:65-72. doi:10.1016/j.breast.2017. 05.001

5. Wang W, Nag S, Zhang X, Wang MH, Wang H. Zhou J and Zhang R. Ribosomal proteins and human diseases: pathogenesis, molecular mechanisms, and therapeutic implications. Med Res Rev. 2015;35 (2):225-285.

6. Rooijers K, Loayza-Puch F, Nijtmans LG, Agami R. Nijtmans LG and Agami R. Ribosome profiling reveals features of normal and disease-associated mitochondrial translation. Nat Commun. 2013;4 (1):2886. doi: $10.1038 /$ ncomms 3886

7. Guillermet J, Saint-Laurent N, Rochaix P, et al. Susini C and Bousquet C. Somatostatin receptor subtype 2 sensitizes human pancreatic cancer cells to death ligand-induced apoptosis. Proc Natl Acad Sci U S A. 2003;100(1):155-160. doi:10.1073/pnas. 0136771100

8. Raimundo N, Song L, Shutt TE, et al. Santos-Sacchi J and Shadel GS. Mitochondrial stress engages E2F1 apoptotic signaling to cause deafness. Cell. 2012;148(4):716-726. doi:10.1016/j.cell.2011.12.027

9. Wang Y, Dong L, Cui H, et al. Ye X and Yao YY. Up-regulation of mitochondrial antioxidation signals in ovarian cancer cells with aggressive biologic behavior. J Zhejiang Univ Sci B. 2011;12 (5):346-356. doi:10.1631/jzus.B1000192

10. Gabriel K, Pfanner N. The mitochondrial machinery for import of precursor proteins. Methods Mol Biol. 2007;390:99-117.

11. He J, Ford HC, Carroll J. Assembly of the membrane domain of ATP synthase in human mitochondria. Proc Natl Acad Sci U S A. 2018;115(12):2988-2993. doi:10.1073/pnas.1722086115

12. O'Brien TW, O'Brien BJ, Norman RA. O'Brien BJ and Norman RA. Nuclear MRP genes and mitochondrial disease. Gene. 2005;3 54:147-151. doi:10.1016/j.gene.2005.03.026

13. Gordon DM, Dancis A, Pain D. Dancis A and Pain D. Mechanisms of mitochondrial protein import. Essays Biochem. 2000;36:61-73. doi: 10.1042/bse0360061

14. Ades IZ. Transport of newly synthesized proteins into mitochondria a review. Mol Cell Biochem. 1982;43(2):113-127. doi:10.1007/ BF00423100

15. Liu L, Luo C, Luo Y, et al. Wu G and Feng Y. MRPL33 and its splicing regulator hnRNPK are required for mitochondria function and implicated in tumor progression. Oncogene. 2018;37(1):86-94. doi:10.1038/onc.2017.314

16. Zhang $\mathrm{L}, \mathrm{Lu} \mathrm{P}$, Yan $\mathrm{L}$, et al. Sun $\mathrm{G}$ and Yang T. MRPL35 Is Up-Regulated in Colorectal Cancer and Regulates Colorectal Cancer Cell Growth and Apoptosis. Am J Pathol. 2019;189 (5):1105-1120. doi:10.1016/j.ajpath.2019.02.003

17. Yoo YA, Kim MJ, Park JK, Chung YM, Lee JH, Chi SG. Kim JS and Yoo YD. Mitochondrial ribosomal protein L41 suppresses cell growth in association with $\mathrm{p} 53$ and p27Kip1. Mol Cell Biol. 2005;25(15):6603-6616. doi:10.1128/MCB.25.15.6603-6616.2005
18. Kim MJ, Yoo YA, Kim HJ, Kang S, Kim YG. Kim JS and Yoo YD. Mitochondrial ribosomal protein L41 mediates serum starvation-induced cell-cycle arrest through an increase of p21 (WAF1/CIP1). Biochem Biophys Res Commun. 2005;338(2):11 79-1184. doi:10.1016/j.bbrc.2005.10.064

19. Lee YK, Lim JJ, Jeoun UW, Min S, Lee EB, Kwon SM. Lee C and Yoon G. Lactate-mediated mitoribosomal defects impair mitochondrial oxidative phosphorylation and promote hepatoma cell invasiveness. J Biol Chem. 2017;292(49):20208-20217. doi:10.1074/jbc.M117.809012

20. Wang K, Li L, Fu L, Yuan Y, Dai H, Zhu T. Zhou Y and Yuan F. Integrated Bioinformatics Analysis the Function of RNA Binding Proteins (RBPs) and Their Prognostic Value in Breast Cancer. Front Pharmacol. 2019;10:140. doi:10.3389/fphar.2019.00140

21. Agrawal V, Kim DY, Kwon Y-G. Kim DY and Kwon YG. Hhip regulates tumor-stroma-mediated upregulation of tumor angiogenesis. Exp Mol Med. 2017;49(1):e289. doi:10.1038/emm.2016.139

22. Mangani D, Weller M, Seyed Sadr E, et al. Binder H and Schneider H. Limited role for transforming growth factor-beta pathway activation-mediated escape from VEGF inhibition in murine glioma models. Neuro Oncol. 2016;18(12):1610-1621. doi:10.1093/neuonc/ now112

23. Rak J, Yu JL, Klement G, Kerbel RS. Klement G and Kerbel RS. Oncogenes and angiogenesis: signaling three-dimensional tumor growth. J Investig Dermatol Symp Proc. 2000;5(1):24-33. doi:10.10 46/j.1087-0024.2000.00012.x

24. Yu S, Sun J, Zhang J, et al. Ma D and Ji C. Aberrant expression and association of VEGF and Dll4/Notch pathway molecules under hypoxia in patients with lung cancer. Histol Histopathol. 2013;28 (2):277-284

25. Tang L, Ma X, Tian Q, Cheng Y, Yao H, Liu Z. Qu X and Han $\mathrm{X}$. Inhibition of angiogenesis and invasion by DMBT is mediated by downregulation of VEGF and MMP-9 through Akt pathway in MDA-MB-231 breast cancer cells. Food Chem Toxicol. 2013;56:204-213. doi:10.1016/j.fct.2013.02.032

26. Chen JS, Zhang YJ. Hu SE and Zhang HQ. [Effects of VEGF-A/ VEGF-C antisense oligodeoxynucleotide on angiogenesis, lymphangiogenesis, and tumor growth of breast cancer]. Ai Zheng. 2007;26 (9):972-976.

27. Alvarez RH, Guarneri V, Icli F, et al. Conte P and Hortobagyi GN. Bevacizumab treatment for advanced breast cancer. Oncologist. 2011;16(12):1684-1697. doi:10.1634/theoncologist.2011-0113

28. Itoh Y, Nagase H. Matrix metalloproteinases in cancer. Essays Biochem. 2002;38:21-36. doi:10.1042/bse0380021

29. Roeb E, Matern S. [Matrix metalloproteinases and colorectal cancer]. Med Klin (Munich). 2003;98(12):763-770. German. doi:10.1007/ s00063-003-1322-5

30. Shin YJ, Kim JH. The role of EZH2 in the regulation of the activity of matrix metalloproteinases in prostate cancer cells. PLoS One. 2012;7(1):e30393. doi:10.1371/journal.pone.0030393

31. Merchant N, Nagaraju GP, Rajitha B, Lammata S, Jella KK, Buchwald ZS. Lakka SS and Ali AN. Matrix metalloproteinases: their functional role in lung cancer. Carcinogenesis. 2017;38 (8):766-780. doi:10.1093/carcin/bgx063

32. Yuan Y, Jiang YC. Sun CK and Chen QM. Role of the tumor microenvironment in tumor progression and the clinical applications (Review). Oncol Rep. 2016;35(5):2499-2515.

33. Zhou Z, Lu ZR. Molecular imaging of the tumor microenvironment. $A d v$ Drug Deliv Rev. 2017;113:24 48. doi:10.1016/j.addr.2016.07.012

34. Gonzalez H, Hagerling C, Werb Z. Hagerling C and Werb Z. Roles of the immune system in cancer: from tumor initiation to metastatic progression. Genes Dev. 2018;32(19-20):1267-1284. doi:10.1101/ gad. 314617.118

35. Mendez-Garcia LA, Nava-Castro KE, Ochoa-Mercado TL, et al. Metastasis: are Cytokines Important Players During Its Development and Progression? J Interferon Cytokine Res. 2019;39 (1):39-55. doi:10.1089/jir.2018.0024 
36. Paduch R. The role of lymphangiogenesis and angiogenesis in tumor metastasis. Cell Oncol. 2016;39(5):397-410. doi:10.1007/s13402016-0281-9

37. Goel S, Duda DG, Xu L, Munn LL, Boucher Y. Fukumura D and Jain RK. Normalization of the vasculature for treatment of cancer and other diseases. Physiol Rev. 2011;91(3):1071-1121. doi:10.1152/ physrev.00038.2010

38. Zhang $\mathrm{B}$. $\mathrm{Hu} \mathrm{Y}$ and Pang $\mathrm{Z}$. Modulating the Tumor Microenvironment to Enhance Tumor Nanomedicine Delivery. Front Pharmacol. 2017;8:952.

39. Bielenberg DR, Zetter BR. The Contribution of Angiogenesis to the Process of Metastasis. Cancer J. 2015;21(4):267-273. doi:10.1097/ PPO.0000000000000138

40. Padera TP, Meijer EFJ, Munn LL. Meijer EF and Munn LL. The Lymphatic System in Disease Processes and Cancer Progression. Annu Rev Biomed Eng. 2016;18(1):125-158. doi:10.1146/annurevbioeng-112315-031200

41. Maimela NR, Liu S, Zhang Y. Liu S and Zhang Y. Fates of CD8+ $\mathrm{T}$ cells in Tumor Microenvironment. Comput Struct Biotechnol J. 2019;17:1-13. doi:10.1016/j.csbj.2018.11.004

42. Fukumura D, Kloepper J, Amoozgar Z. Duda DG and Jain RK. Enhancing cancer immunotherapy using antiangiogenics: opportunities and challenges. Nat Rev Clin Oncol. 2018;15(5):325-340.

43. Muller L, Aigner P, Type SD. I Interferons and Natural Killer Cell Regulation in Cancer. Front Immunol. 2017;8:304. doi:10.3389/ fimmu.2017.00304

44. Schaaf MB, Garg AD, Agostinis P. Garg AD and Agostinis P. Defining the role of the tumor vasculature in antitumor immunity and immunotherapy. Cell Death Dis. 2018;9(2):115. doi:10.1038/ s41419-017-0061-0
45. Kim HW, Kim JE, Hwang MH, Jeon YH, Lee SW, Lee J. Zeon SK and Ahn BC. Enhancement of natural killer cell cytotoxicity by sodium/iodide symporter gene-mediated radioiodine pretreatment in breast cancer cells. PLoS One. 2013;8(8):e70194. doi:10.1371/journal.pone.0070194

46. Zappasodi R. Merghoub T and Wolchok JD. Emerging Concepts for Immune Checkpoint Blockade-Based Combination Therapies. Cancer Cell. 2018;34(4):690.

47. Barrueto L, Caminero F, Cash L, Makris C, Lamichhane P, Deshmukh RR. Lamichhane P and Deshmukh RR. Resistance to Checkpoint Inhibition in Cancer Immunotherapy. Transl Oncol. 2020;13(3):100738. doi:10.1016/j.tranon.2019.12.010

48. Marhelava K, Pilch Z, Bajor M, Graczyk-Jarzynka A, Zagozdzon R. Targeting Negative and Positive Immune Checkpoints with Monoclonal Antibodies in Therapy of Cancer. Cancers. 2019;11 (11):11. doi:10.3390/cancers 11111756

49. Rowshanravan B, Halliday N, Sansom DMCTLA-4. a moving target in immunotherapy. Blood. 2018;131(1):58-67. doi:10.1182/blood2017-06-741033

50. Srinivasan M, Lu D, Eri R, Brand DD, Haque A, Blum JS. Haque A and Blum JS. CD80 binding polyproline helical peptide inhibits T cell activation. J Biol Chem. 2005;280(11):10149-10155. doi:10. 1074/jbc.M409521200

51. Grosso JF, Jure-Kunkel MNCTLA-4. blockade in tumor models: an overview of preclinical and translational research. Cancer Immun. 2013;13:5

\section{Publish your work in this journal}

OncoTargets and Therapy is an international, peer-reviewed, open access journal focusing on the pathological basis of all cancers, potential targets for therapy and treatment protocols employed to improve the management of cancer patients. The journal also focuses on the impact of management programs and new therapeutic agents and protocols on patient perspectives such as quality of life, adherence and satisfaction. The manuscript management system is completely online and includes a very quick and fair peer-review system, which is all easy to use. Visit http://www.dovepress.com/ testimonials.php to read real quotes from published authors. 